\title{
Microstructure and thermal expansion of copper- based amorphous alloys during structural relaxation
}

\author{
Jin-bei Zhao, *Xin-hui Fan, Bing Li, Ke Yang, Yi-long Kong, Zhao Wang \\ College of Materials and Chemical Engineering, Xi'an Technological University, Xi'an 710021, China
}

\begin{abstract}
Cu}_{43} \mathrm{Zr}_{48} \mathrm{Al}_{9}\right)_{98} \mathrm{Y}_{2}$ amorphous alloy bar was prepared by the arc melting copper mold absorption casting method, and then, the amorphous alloy was annealed at different temperatures for different times. The influence of heating rate on thermal expansion and thermal stability was studied by thermomechanical analysis (TMA), and the microstructure evolution of the amorphous alloy during structural relaxation and crystallization was studied by XRD and TEM. Results show that the structural evolution behavior of the $\left(\mathrm{Cu}_{43} \mathrm{Zr}_{48} \mathrm{Al}_{9}\right)_{98} \mathrm{Y}_{2}$ amorphous alloy can be divided into five different stages (structural relaxation preparation stage, structural relaxation stage, first crystallization stage, second crystallization stage, and grain growth stage). When the heating rate is $20 \mathrm{~K} /$ min, the amorphous alloy has the smallest thermal expansion coefficient and the best thermal stability. The width of the supercooled liquid region is $66.42 \mathrm{~K}$. Samples with different relaxation states were prepared by annealing at the heating rate of $20 \mathrm{~K} / \mathrm{min}$. The structural evolution of amorphous alloys with different relaxation states is as follows: amorphous $\rightarrow \mathrm{CuZr} 2+\mathrm{AlCu}_{2} \mathrm{Zr}_{7} \rightarrow \mathrm{CuZr}_{2}+\mathrm{AlCu}_{2} \mathrm{Zr}_{7}+\mathrm{CuZr}(\mathrm{B} 2)+\mathrm{CuZr}(\mathrm{M})+\mathrm{Cu}_{10} \mathrm{Zr}_{7} \rightarrow \mathrm{CuZr}_{2}+$ $\mathrm{AlCu}_{2} \mathrm{Zr}_{7}+\mathrm{CuZr}(\mathrm{B} 2)+\mathrm{CuZr}(\mathrm{M})$. After annealing at $706 \mathrm{~K}$ and $726 \mathrm{~K}$ (in the supercooled liquid region) for 1.5 $\mathrm{h}$, the amorphous-nanocrystalline composites were obtained. When the annealing temperature is $706 \mathrm{~K}$, the crystallization process of the sample is as follows: amorphous $\rightarrow \mathrm{Cu}_{10} \mathrm{Zr}_{7} \rightarrow \mathrm{Cu}_{10} \mathrm{Zr}_{7}+\mathrm{CuZr}$, and for the sample at $726 \mathrm{~K}$, it is as follows: amorphous $\rightarrow \mathrm{CuZr}_{2}+\mathrm{AlCu}_{2} \mathrm{Zr}_{7}+\mathrm{Cu}_{10} \mathrm{Zr}_{7} \rightarrow \mathrm{Cu}_{10} \mathrm{Zr}_{7}+\mathrm{CuZr} r_{2} \rightarrow \mathrm{CuZr}_{2}+\mathrm{CuZr}(\mathrm{B} 2)+$ $\mathrm{Cu}_{10} \mathrm{Zr}_{7}$.
\end{abstract}

Key words: amorphous-nanocrystalline composite materials; structural relaxation; microstructure; thermal expansion; thermal stability

CLC numbers: TG146.1 ${ }^{+} 1 \quad$ Document code: A Article ID: 1672-6421(2020)01-008-07

$\mathrm{I}$

$n$ recent years, amorphous materials have gradually

become the key materials of some products, such as amorphous motor and amorphous coating, owing to their unique microstructure, good mechanical properties, and application prospects ${ }^{[1-5]}$. Structural relaxation and crystallization occurring during annealing change the physical, chemical, and mechanical properties of amorphous alloys ${ }^{[6-11]}$. The physical properties of the amorphous alloy (e.g., coefficient of thermal expansion) can be tested to further understand the microstructure transformation of the amorphous alloy ${ }^{[12-14]}$. Previous studies ${ }^{[15]}$ showed that structural relaxation occurs as the metallic glass $\mathrm{Zr}_{57} \mathrm{Cu}_{15.4} \mathrm{Ni}_{12.6} \mathrm{Al}_{10} \mathrm{Nb}_{5}$ is annealed at a temperature slightly higher than the glass transition

\begin{abstract}
*Xin-hui Fan
Male, Ph.D, Professor. Research interest: amorphous alloys. He has been the leader of one National Natural Science Foundation and three projects in the General Armament Department, China, has been awarded 6 provincial and ministerial level science and technology awards, and holds 5 invention patents. To date, he has published more than 60 academic papers.
\end{abstract}

E-mail: fanxh2002@xatu.edu.cn

Received: 2019-08-21; Accepted: 2019-11-30 temperature. When the above mentioned material was annealed at temperatures above the glass transition temperature but slightly below the crystallization temperature, a crystallization transition over a longer period of time occurred owing to structural relaxation. Yuan X P, et al ${ }^{[16]}$ annealed the sample at $T_{x}+100{ }^{\circ} \mathrm{C}\left(T_{x}\right.$ is the initial crystallization temperature). The obtained results show that the $\mathrm{Cu}_{46} \mathrm{Zr}_{44} \mathrm{Al}_{5} \mathrm{Nb}_{5}$ amorphous alloy has good thermal stability, and the crystallization type is mainly a diffusion-controlled eutectic transformation. During the isothermal crystallization annealing at $T_{x}+$ $100{ }^{\circ} \mathrm{C}$, the size and volume fraction of $\mathrm{Cu}_{10} \mathrm{Zr}_{7}$ phases gradually increased with an increase in holding time. Cao Chengcheng ${ }^{[17]}$ found the properties of the ironbased amorphous alloy were significantly improved after pre-annealing at $660 \mathrm{~K}$ for 5-10 min. Chen Q $\mathrm{J}$, et al ${ }^{[18]}$ studied the thermal expansion property of iron-cobalt-based bulk amorphous alloys. The results show that the internal thermal expansion behavior of $\mathrm{Fe}_{24+\mathrm{x}} \mathrm{Co}_{24-\mathrm{x}} \mathrm{Cr}_{15} \mathrm{Mo}_{14} \mathrm{C}_{15} \mathrm{~B}_{6} \mathrm{Y}_{2}(x=0,2,4,6$, and 8) amorphous alloys is similar at different temperature ranges. As the Co content decreases, the secondary 
crystallization initiation temperature of the iron-cobalt-based amorphous alloy increases. Guan Heng ${ }^{[19]}$ studied the structural transformation behavior of Ti-based bulk metallic glass using the thermal expansion method. The results show that nanograins of approximately $20 \mathrm{~nm}$ are formed after thermal expansion. However, the microstructure evolution of copperbased amorphous alloys during structural relaxation and its effects on thermal expansion and thermal stability have rarely been reported.

$\mathrm{CuZr-based} \mathrm{bulk} \mathrm{amorphous} \mathrm{alloys} \mathrm{have} \mathrm{strong} \mathrm{glass-}$ forming ability, low cost, and excellent mechanical properties, which make them most likely to become a new type of intensely researched structural materials. In this study, the $\left(\mathrm{Cu}_{43} \mathrm{Zr}_{48} \mathrm{Al}_{9}\right)_{98} \mathrm{Y}_{2}$ alloy, which has an excellent amorphous forming ability and good thermal stability, was selected. The effect of the degree of structural relaxation on the thermal expansion and thermal stability of amorphous alloys was studied by controlling the heating rate, and the appropriate heating rate was chosen for annealing. The relationship between the microstructure evolution of the amorphous matrix and the thermal expansion and thermal stability during structural relaxation by annealing was determined. Thereby, the law of structural relaxation in amorphous alloys and the crystallization phenomenon during structural relaxation were studied.

\section{Experiment}

The experimental raw materials $\mathrm{Cu}$ (99.9\%), $\mathrm{Zr}$ (99.9\%), Al (99.9\%), and $\mathrm{Y}(99.9 \%)$ were arc melted in a water-cooled copper crucible according to the ratio of $\left(\mathrm{Cu}_{43} \mathrm{Zr}_{48} \mathrm{Al}_{9}\right)_{98} \mathrm{Y}_{2}$, to obtain an ingot weight of $30 \mathrm{~g}$. Then, the alloy ingot was remelted for five cycles for homogeneity, expecting a mass loss of the alloy ingot of less than $0.5 \%$. Finally, the amorphous alloy rod sample with a diameter of $5 \mathrm{~mm}$ and a height of 1.5 $\mathrm{mm}$ was prepared by copper mold suction casting.

To study the effects of structural relaxation on the thermal expansion and thermal stability of amorphous alloys, thermomechanical analysis (TMA) was used to test the thermal expansion and thermal stability of amorphous alloys at different heating rates of $5,10,20,30,40$, and $50 \mathrm{~K} / \mathrm{min}$. To study the microstructure evolution of the alloys during structural relaxation, the ingots were cooled in water immediately after holding for different times $(0.5,1.0$, and $1.5 \mathrm{~h})$ at different temperatures of $706,726,746,878$, and $938 \mathrm{~K}$, because quick cooling can prevent an amorphous alloy from continuing to crystallize and maintains the microstructure after annealing. The microstructures of the samples were analyzed by X-ray diffraction (XRD) and transmission electron microscopy (TEM), with the scanning speed of $0.02 \% \mathrm{~min}$ and scanning range of $20-80^{\circ}$, and the $\mathrm{Cu}-\mathrm{K} \alpha$ radiation $(\lambda=1.54056 \mathrm{~nm})$ was used. The thermodynamic performance of the as-cast sample was analyzed by DSC, under a heating rate of $20 \mathrm{~K} / \mathrm{min}$, and argon gas was used as the shielding gas.

\section{Results and discussion}

\subsection{Structural identification and thermodynamic properties of as-cast amorphous alloys}

Figure 1(a) shows the XRD pattern of the as-cast $\left(\mathrm{Cu}_{43} \mathrm{Zr}_{48} \mathrm{Al}_{9}\right)_{98} \mathrm{Y}_{2}$ amorphous alloy. It is observed that there is a broad diffusion scattering peak in the range of $35-50^{\circ}$. This is a diffraction peak of a typical amorphous structure, indicating that the ascast sample is amorphous. Considering the low resolution nature of XRD, to ensure the absence of nanocrystals in the sample, the microstructure was further observed by TEM. Figure 1(c) shows its TEM image. The selected area electron diffraction pattern exhibits a diffuse scattering halo. The high resolution electron image shows typically amorphous without the presence of nanocrystals, and its structure is uniform. Figure 1(b) is the DSC curve of the as-cast $\left(\mathrm{Cu}_{43} \mathrm{Zr}_{48} \mathrm{Al}_{9}\right)_{98} \mathrm{Y}_{2}$ amorphous alloy. The glass transition temperature $T_{\mathrm{g}}$, the initial crystallization temperature $T_{x}$, and the crystallization peak-topeak temperatures $T_{\mathrm{p} 1}$ and $T_{\mathrm{p} 2}$ are $715,780,790$, and $913 \mathrm{~K}$, respectively, and the width of the supercooled liquid region is $\Delta T_{x}$ of $65 \mathrm{~K}$ and $\Delta T_{\mathrm{p}}$ of $123 \mathrm{~K}$. The value of $\Delta T_{\mathrm{p}}$ determines the width of the heat treatment temperature interval, and a greater $\Delta T_{\mathrm{p}}$ is helpful to the precipitation of the crystallization phase during heat treatment.
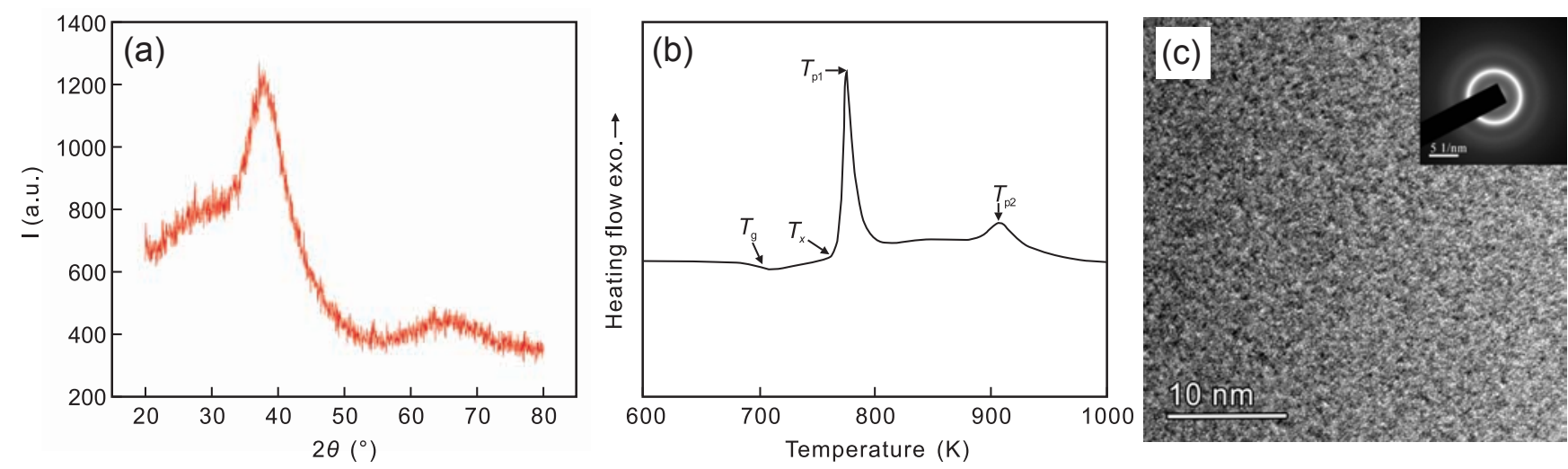

Fig. 1: XRD pattern (a), DSC curve (b) and TEM image (c) of $\left(\mathrm{Cu}_{43} \mathrm{Zr}_{48} \mathrm{Al}_{9}\right)_{98} \mathrm{Y}_{2}$ 


\subsection{Effect of structural relaxation on thermal stability and thermal expansion of amorphous alloys}

Figure 2 shows the TMA curves of the $\left(\mathrm{Cu}_{43} \mathrm{Zr}_{48} \mathrm{Al}_{9}\right)_{98} \mathrm{Y}_{2}$ amorphous alloy at different heating rates and its thermal expansion coefficient curves. It can be seen that both the TMA curves and the thermal expansion coefficient curve are moderate before $710 \mathrm{~K}$, the coefficient of thermal expansion has no obvious change, indicating the atomic arrangement of the amorphous alloy is still an amorphous structure. At this stage, the mobility of the amorphous internal atoms is weak due to the low temperature, which is insufficient to achieve the cooperative diffusion required for structural relaxation. The change in the thermal expansion coefficient of the stage is mainly caused by the anharmonic vibration of internal atoms. The free volume ${ }^{[20]}$ in the amorphous alloy gradually increases with an increase in the temperature, and the anharmonic vibration of internal atoms changes the structure of short-range order of the amorphous alloy, which provides a structural basis for long-range diffusion and order transformation. When the temperature reaches the glass transition temperature, the thermal expansion coefficient of the amorphous alloy considerably decreases, which indicates the structural relaxation of the amorphous alloy. The structural relaxation mainly includes the change in the topological shortrange and chemical short-range order structures ${ }^{[21]}$. The change in the topological short-range order structure is mainly attributed to an increase in the activity of atoms inside the amorphous alloy caused by the discharge of excess free volume in the quenched amorphous alloy during the initial stage of structural relaxation combined with the surrounding free volume. The free volume of the amorphous alloy decreases continuously, which makes the coefficient of thermal expansion of the amorphous alloy continuously reduce, therefore, the structural transformation occurs in the amorphous alloy.

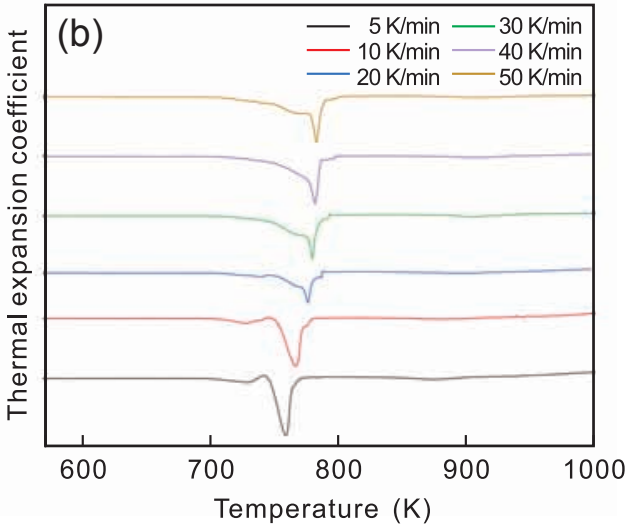

Fig. 2: TMA curves (a) and its thermal expansion coefficient curves (b) of $\left(\mathrm{Cu}_{43} \mathrm{Zr}_{48} \mathrm{Al}_{9}\right)_{98} \mathrm{Y}_{2}$ amorphous alloy at different heating rates

As the temperature increases, the coefficient of thermal expansion sharply decreases due to the changes in the chemical short-range order structure during structural relaxation. The main cause of these changes is the rearrangement of the atomic structure caused by atomic diffusion during structural relaxation. As the temperature increases, the ability of atoms to migrate continuously increases. Because of the long-range diffusion of atoms, the atomic diffusion of amorphous alloy tends to be regularly arranged. This causes the free volume of the amorphous alloy to disappear faster, resulting in a sharp decrease in the thermal expansion coefficient of the amorphous alloy. This process is the first crystallization transformation of the copper-based amorphous alloy, and the temperature corresponding to the minimum point of the thermal expansion coefficient is $T_{x}$. Meanwhile, it can be seen from Fig. 2(a) that the second crystallization of the amorphous alloy occurs as the temperature continues to increase. The starting point of the crystallization temperature is shown as the dotted line. It is observed that the coefficient of thermal expansion decreases slightly. This phenomenon is related to the type of crystal phases produced by the first crystallization and the surplus of free volume. As the temperature continues to increase, the amorphous alloy is transformed into a crystalline alloy completely, and the grain size increases according to the rise in the temperature. At this stage, the thermal expansion is caused by the expansion on heating and contraction on cooling. In general, according to the change in the thermal expansion rate, the amorphous alloy experiences five stages during the heating process. The first stage is the structural relaxation preparation stage at the temperature range of $550 \mathrm{~K}-T_{\mathrm{g}}$, and the thermal expansion coefficient remains unchanged. The second stage is the structural relaxation stage at the temperature range of $T_{\mathrm{g}}$ $T_{x}$, and the thermal expansion coefficient gradually decreases. The third stage is the first crystallization stage at $T_{x}-800 \mathrm{~K}$, and the thermal expansion coefficient increases. The fourth stage is the second crystallization stage at 800-900 K, and the thermal expansion coefficient gradually decreases. The fifth stage is the grain growth stage at 900-1000 K, and the thermal expansion coefficient changes according to the thermal expansion and contraction law.

Figure 2 shows that different heating rates affect the structural relaxation process of amorphous alloys. As the heating rate increases, the difference between the thermal expansion coefficient of as-cast $\left(\mathrm{Cu}_{43} \mathrm{Zr}_{48} \mathrm{Al}_{9}\right)_{98} \mathrm{Y}_{2}$ amorphous 
alloy and the minimum coefficient of thermal expansion firstly decreases and then increases, which is related to the degree of structural relaxation of amorphous alloys, nucleation rate and growth rate of the crystal phase. When the heating rate is $20 \mathrm{~K} / \mathrm{min}$, the difference between the thermal expansion coefficient of as-cast $\left(\mathrm{Cu}_{43} \mathrm{Zr}_{48} \mathrm{Al}_{9}\right)_{98} \mathrm{Y}_{2}$ amorphous alloy and the minimum coefficient of thermal expansion is the smallest, indicating that its thermal stability is better. Table 1 shows the effect of heating rate on the glass transition temperature and initial crystallization temperature of the amorphous alloy. As the heating rate increases, the glass transition temperature gradually increases, and the initial crystallization temperature firstly increases and then decreases. The width of the supercooled liquid region also firstly increases and then decreases. The width of the supercooled liquid region is closely related to the thermal stability of the amorphous alloy. The wider the width of the supercooled liquid region, the better its thermal stability. Therefore, the thermal stability of the amorphous alloy firstly increases and then decreases. When the heating rate is $20 \mathrm{~K} / \mathrm{min}$, the width of the supercooled liquid region is the largest, which is $66.42 \mathrm{~K}$, and the amorphous alloy has the best thermal stability. Therefore, the heating rate was selected to be $20 \mathrm{~K} / \mathrm{min}$ when the $\left(\mathrm{Cu}_{43} \mathrm{Zr}_{48} \mathrm{Al}_{9}\right)_{98} \mathrm{Y}_{2}$ amorphous alloy was annealed.

Table 1: $\left(\mathrm{Cu}_{43} \mathrm{Zr}_{48} \mathrm{Al}_{9}\right)_{98} \mathrm{Y}_{2}$ characteristic points at different heating rates

\begin{tabular}{rrrr} 
Heating rates & $T_{\mathrm{g}}(\mathbf{K})$ & $T_{\mathrm{x}}(\mathbf{K})$ & $\Delta \boldsymbol{T}(\mathbf{K})$ \\
\hline $5 \mathrm{~K} / \mathrm{min}$ & 713.68 & 770.38 & 57.15 \\
$10 \mathrm{~K} / \mathrm{min}$ & 710.5 & 774.24 & 59.74 \\
$20 \mathrm{~K} / \mathrm{min}$ & 711.95 & 782.37 & 66.42 \\
$30 \mathrm{~K} / \mathrm{min}$ & 727.07 & 786.7 & 59.63 \\
$40 \mathrm{~K} / \mathrm{min}$ & 727.57 & 787.08 & 59.51 \\
$50 \mathrm{~K} / \mathrm{min}$ & 728.11 & 785.37 & 57.26 \\
\hline
\end{tabular}

\subsection{Microstructure development of $\left(\mathrm{Cu}_{43} \mathrm{Zr}_{48} \mathrm{Al}_{9}\right)_{98} \mathrm{Y}_{2}$ amorphous alloy during structural relaxation process and heat treatment process}

2.3.1 Microstructure development of the $\left(\mathrm{Cu}_{43} \mathrm{Zr}_{48} \mathrm{Al}_{9}\right)_{98} \mathrm{Y}_{2}$ amorphous alloy during structural relaxation

To study the effect of annealing temperature on the microstructure of the $\left(\mathrm{Cu}_{43} \mathrm{Zr}_{48} \mathrm{Al}_{9}\right)_{98} \mathrm{Y}_{2}$ amorphous alloy, different annealing temperatures were selected, according to the DSC curve [Fig. 1(b)], as follows: $T_{1}(706 \mathrm{~K})<T_{\mathrm{g}}(715 \mathrm{~K})$ $<T_{2}(726 \mathrm{~K})<T_{3}(746 \mathrm{~K})<T_{x}(780 \mathrm{~K})<T_{\mathrm{P} 1}(790 \mathrm{~K})<T_{4}(878$ $\mathrm{K})<T_{\mathrm{P} 2}(913 \mathrm{~K})<T_{5}(938 \mathrm{~K})$. The annealing time was $0.5 \mathrm{~h}$.

The XRD patterns of the $\left(\mathrm{Cu}_{43} \mathrm{Zr}_{48} \mathrm{Al}_{9}\right)_{98} \mathrm{Y}_{2}$ amorphous alloys with different annealing temperatures were analyzed by phase analysis. The results of the analysis are shown in Fig. 3. It can be seen from Fig. 3 that the degree of crystallization and the crystalline phase of the $\left(\mathrm{Cu}_{43} \mathrm{Zr}_{48} \mathrm{Al}_{9}\right)_{98} \mathrm{Y}_{2}$ amorphous alloys in different relaxation states are different. At the annealing temperature of $706 \mathrm{~K}$, the $\left(\mathrm{Cu}_{43} \mathrm{Zr}_{48} \mathrm{Al}_{9}\right)_{98} \mathrm{Y}_{2}$ amorphous alloy still exhibits a diffuse scattering peak of the amorphous state. Figure 4(a) shows the TEM image of the $\left(\mathrm{Cu}_{43} \mathrm{Zr}_{48} \mathrm{Al}_{9}\right)_{98} \mathrm{Y}_{2}$ amorphous alloy at the annealing temperature of $706 \mathrm{~K}$. The selected area electron diffraction pattern is a diffuse scattering

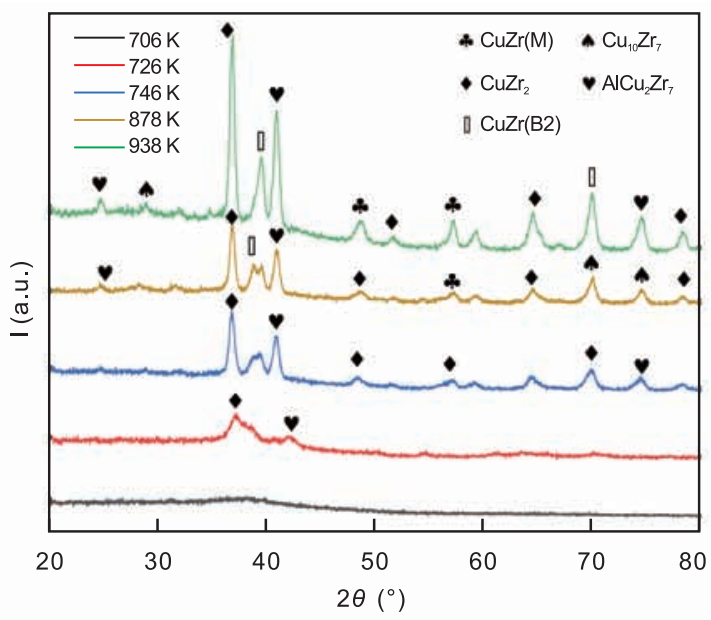

Fig. 3: XRD patterns of $\left(\mathrm{Cu}_{43} \mathrm{Zr}_{48} \mathrm{Al}_{9}\right)_{98} \mathrm{Y}_{2}$ amorphous alloy at different annealing temperatures
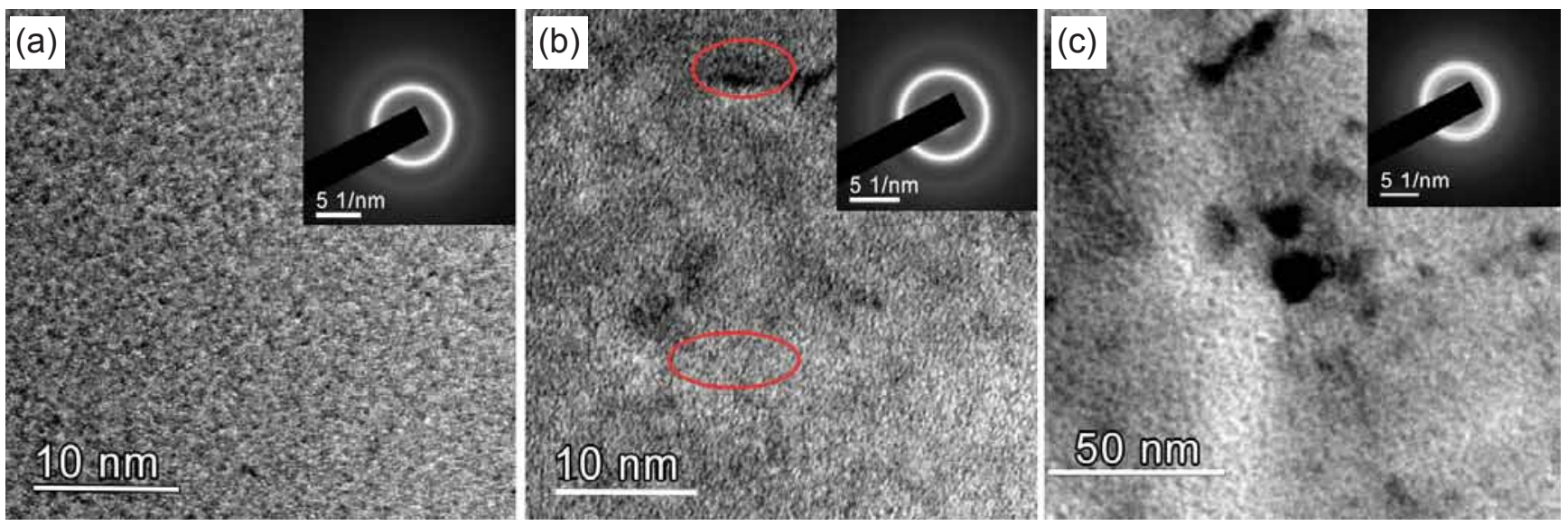

Fig. 4: TEM images of $\left(\mathrm{Cu}_{43} \mathrm{Zr}_{48} \mathrm{Al}_{9}\right)_{98} \mathrm{Y}_{2}$ amorphous alloys with annealing temperatures of $706 \mathrm{~K}(\mathrm{a}), 726 \mathrm{~K}$ (b), and $746 \mathrm{~K}$ (c) 
halo, and the high-resolution electron image shows the amorphous structure without any nanocrystalline components. This is because during the annealing process, the internal stress accumulated in the $\left(\mathrm{Cu}_{43} \mathrm{Zr}_{48} \mathrm{Al}_{9}\right)_{98} \mathrm{Y}_{2}$ amorphous alloy is released, meanwhile, structural relaxation occurs, which results in a decrease in the amorphous state. When annealing at $726 \mathrm{~K}$ and $746 \mathrm{~K}$, the crystal diffraction peaks that appear in Fig. 3, the crystallized peaks of the sharp $\mathrm{CuZr}_{2}$ phase and the $\mathrm{AlCu}_{2} \mathrm{Zr}_{7}$ phase are superimposed on the amorphous diffuse scattering peak, and the crystallization peaks of the $\mathrm{CuZr}_{2}$ and $\mathrm{AlCu}_{2} \mathrm{Zr}_{7}$ phases increase with an increase in annealing temperature.

Figures 4(b) and (c) show the TEM images of $\left(\mathrm{Cu}_{43} \mathrm{Zr}_{48} \mathrm{Al}_{9}\right)_{98} \mathrm{Y}_{2}$ amorphous alloy annealed at $726 \mathrm{~K}$ and $746 \mathrm{~K}$, respectively. A crystal phase can be seen in some areas of the dark field image in Fig. 4(b). The average size of nanocrystalline components is relatively small, approximately $12 \mathrm{~nm}$. Figure 4(c) shows a diffuse diffraction ring in the electron diffraction image. It can be observed that several crystal diffraction spots appear on the diffusion ring at a lower diffraction angle. The diffraction spots and ring were analyzed to determine the nanocrystalline phases on the substrate. In addition, Fig. 4(c) shows that there are two glassy-phase alloys. It was found ${ }^{[22]}$ that another metal element mixed with the main component of the alloy system can be used to prepare two glassy-phases in one amorphous alloy. The mixing heat between two elements of $\left(\mathrm{Cu}_{43} \mathrm{Zr}_{48} \mathrm{Al}_{9}\right)_{98} \mathrm{Y}_{2}$ amorphous alloy is as follows: $\mathrm{Zr}-\mathrm{Cu}:-23 \mathrm{~kJ} / \mathrm{mol}, \mathrm{Zr}-\mathrm{Al}:-49 \mathrm{~kJ} /$ mol, Zr-Y: $9 \mathrm{~kJ} / \mathrm{mol}, \mathrm{Cu}-\mathrm{Al}:-44 \mathrm{~kJ} / \mathrm{mol}, \mathrm{Cu}-\mathrm{Y}:-22 \mathrm{~kJ} / \mathrm{mol}$, and Al-Y: $-38 \mathrm{~kJ} / \mathrm{mol}$; the elements $\mathrm{Zr}, \mathrm{Cu}$, and $\mathrm{Al}$ have a relatively strong affinity with each other. During the annealing process, $\mathrm{Cu}$ and $\mathrm{Zr}$ preferentially capture the solute component $\mathrm{Al}$, and component $\mathrm{Y}$ is mainly trapped by $\mathrm{Cu}$ and $\mathrm{Al}$ due to $\mathrm{Zr}$ and $\mathrm{Y}$ having a positive mixing heat. The $\left(\mathrm{Cu}_{43} \mathrm{Zr}_{48} \mathrm{Al}_{9}\right)_{98} \mathrm{Y}_{2}$ amorphous alloy is water-cooled after annealing, and two glassy-phases are formed in local regions due to the rapid cooling rate.

When the annealing temperature is $726 \mathrm{~K}$, the nanocrystalline phases are $\mathrm{CuZr}_{2}$ and $\mathrm{AlCu}_{2} \mathrm{Zr}_{7}$. When the temperature is $746 \mathrm{~K}$, the crystallization phases of $\mathrm{CuZr}(\mathrm{B} 2)$, $\mathrm{CuZr}(\mathrm{M})$ and $\mathrm{Cu}_{10} \mathrm{Zr}_{7}$ begin to precipitate. However, when the annealing temperature is $938 \mathrm{~K}$, the $\mathrm{Cu}_{10} \mathrm{Zr}_{7}$ phase disappears, because the $\mathrm{Cu}_{10} \mathrm{Zr}_{7}+\mathrm{CuZr}_{2} \rightarrow \mathrm{CuZr}$ reaction occurs, which is an exothermic reaction. It can be inferred that there is an exothermic peak between $T_{4}$ and $T_{5}$, which corresponds to the second crystallization peak in Fig. 1(b). The microstructure evolution of samples with different structural relaxation is stated as follows: amorphous $\rightarrow \mathrm{CuZr}_{2}+\mathrm{AlCu}_{2} \mathrm{Zr}_{7} \rightarrow \mathrm{CuZr}_{2}$ $+\mathrm{AlCu}_{2} \mathrm{Zr}_{7}+\mathrm{CuZr}(\mathrm{B} 2)+\mathrm{CuZr}(\mathrm{M})+\mathrm{Cu}_{10} \mathrm{Zr}_{7} \rightarrow \mathrm{CuZr}_{2}+$ $\mathrm{AlCu}_{2} \mathrm{Zr}_{7}+\mathrm{CuZr}(\mathrm{B} 2)+\mathrm{CuZr}(\mathrm{M})$.

\subsubsection{Microstructure development of samples subjected to low temperature heat treatment}

Figure 5 shows the XRD patterns of the $\left(\mathrm{Cu}_{43} \mathrm{Zr}_{48} \mathrm{Al}_{9}\right)_{98} \mathrm{Y}_{2}$ amorphous alloy at 706, 726, and $746 \mathrm{~K}$. It can be seen that when the $\left(\mathrm{Cu}_{43} \mathrm{Zr}_{48} \mathrm{Al}_{9}\right)_{98} \mathrm{Y}_{2}$ amorphous alloy remains at the same annealing temperature for different periods of times, the degree of crystallization of the alloys was different, the degree of crystallization of the $\left(\mathrm{Cu}_{43} \mathrm{Zr}_{48} \mathrm{Al}_{9}\right)_{98} \mathrm{Y}_{2}$ amorphous alloy at different annealing temperatures for the same time is also different. The XRD pattern of the $\left(\mathrm{Cu}_{43} \mathrm{Zr}_{48} \mathrm{Al}_{9}\right)_{98} \mathrm{Y}_{2}$ amorphous alloy is subjected to phase analysis. It can be found that the number of crystal diffraction peaks increases continuously and their intensity also increases with an increase in heat treatment time, and the XRD pattern of the amorphous alloy exhibits diffuse diffraction peaks after crystallization. The Scherer equation (1) shows that the grain size of the alloy $(D)$ is inversely proportional to the full width at half maximum of the crystal diffraction peak $(\beta)$,

$$
D=K \lambda / \beta \cos \theta
$$

$K$ is Scherrer constant, $\theta$ is the Bragg diffraction angle, $\lambda$ is the $\mathrm{X}$-ray wavelength.

According to the equation, the calculated grain sizes of the $\left(\mathrm{Cu}_{43} \mathrm{Zr}_{48} \mathrm{Al}_{9}\right)_{98} \mathrm{Y}_{2}$ amorphous alloy are $13.9 \mathrm{~nm}$ after a $1.5 \mathrm{~h}$ treatment at $706 \mathrm{~K}, 9.6 \mathrm{~nm}$ after $1 \mathrm{~h}$ treatment at $726 \mathrm{~K}$, and $17.4 \mathrm{~nm}$ after $1.5 \mathrm{~h}$ treatment at $726 \mathrm{~K}$. These results show that the suitable annealing temperature and holding time help to refine the crystal grains of $\left(\mathrm{Cu}_{43} \mathrm{Zr}_{48} \mathrm{Al}_{9}\right)_{98} \mathrm{Y}_{2}$ amorphous alloys.

Figure 6(a) shows TEM image of the $\left(\mathrm{Cu}_{43} \mathrm{Zr}_{48} \mathrm{Al}_{9}\right)_{98} \mathrm{Y}_{2}$ amorphous alloy after heat treatment at $706 \mathrm{~K}$ for $1.5 \mathrm{~h}$. White crystal grains can be observed in the region of the dark field image. The analysis of the diffraction ring and diffraction spots shows that the crystal phases precipitated in the amorphous matrix are the $\mathrm{Cu}_{10} \mathrm{Zr}_{7}$ and $\mathrm{CuZr}_{2}$ phases, and the nanocrystal grains are small, approximately $10 \mathrm{~nm}$. This observation is consistent with the calculated grain size, and the nanocrystal grains in the amorphous matrix are also
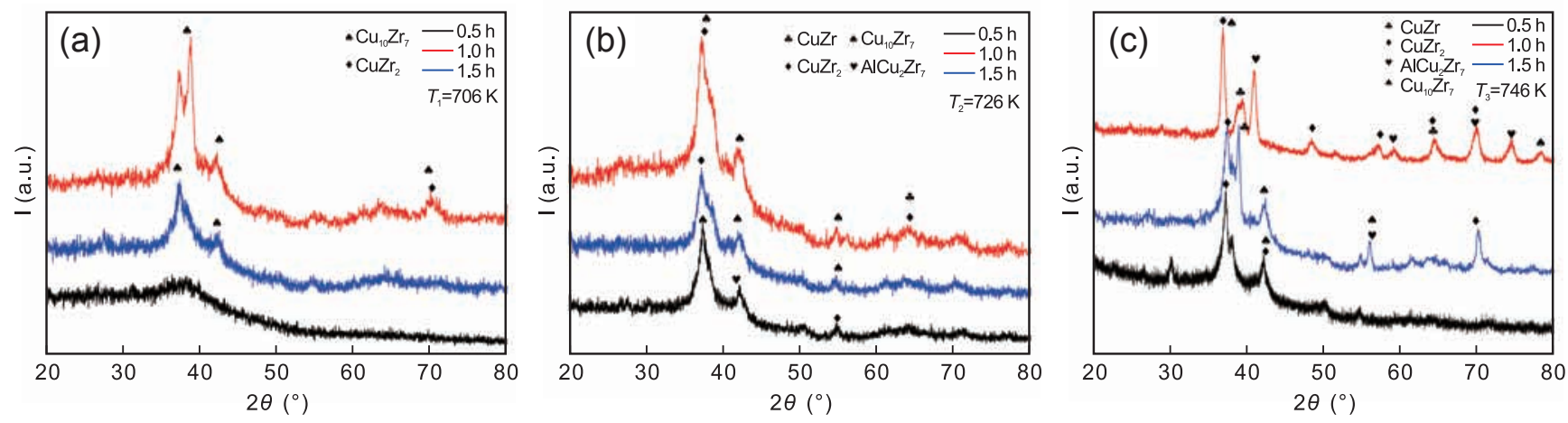

Fig. 5: XRD patterns of $\left(\mathrm{Cu}_{43} \mathrm{Zr}_{48} \mathrm{Al}_{9}\right)_{98} \mathrm{Y}_{2}$ amorphous alloy at different annealing temperatures and annealing times 

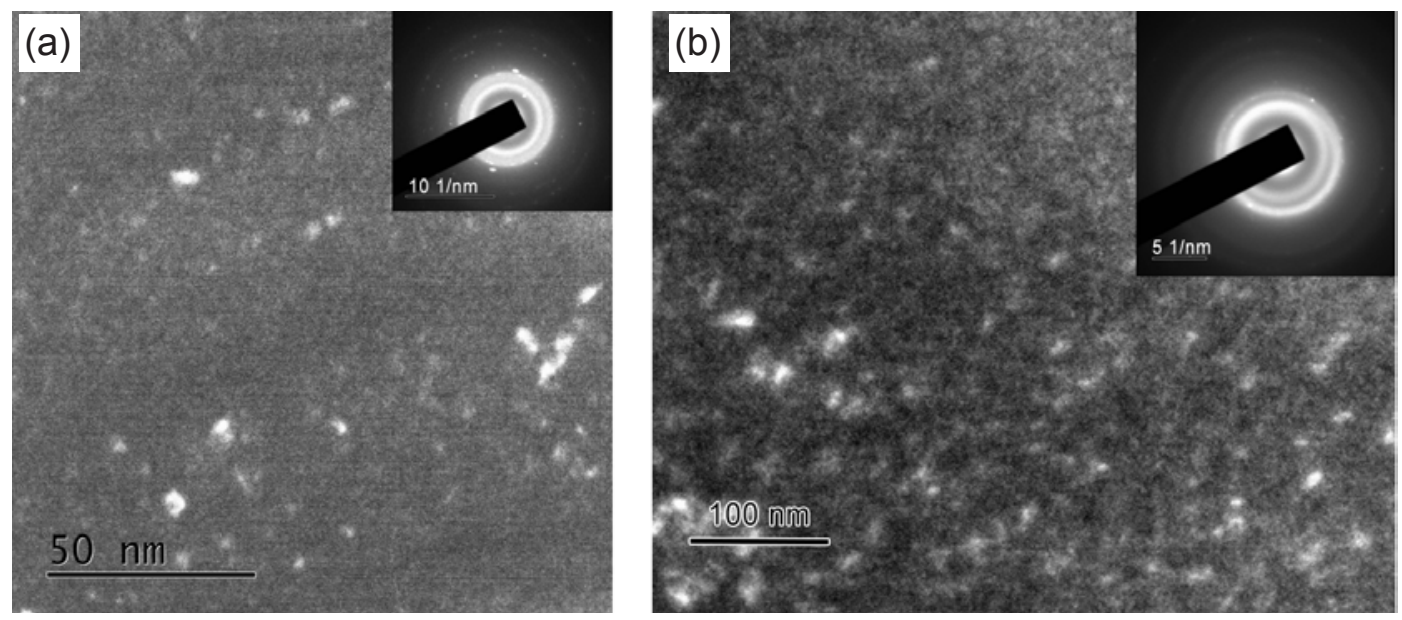

Fig. 6: TEM images of $\left(\mathrm{Cu}_{43} \mathrm{Zr}_{48} \mathrm{Al}_{9}\right)_{98} \mathrm{Y}_{2}$ amorphous alloy after annealing at $706 \mathrm{~K}$ (a) and $726 \mathrm{~K}$ (b) for $1.5 \mathrm{~h}$

relatively small. Figure 6(b) shows the TEM image of the $\left(\mathrm{Cu}_{43} \mathrm{Zr}_{48} \mathrm{Al}_{9}\right)_{98} \mathrm{Y}_{2}$ amorphous alloy after heat treatment at $726 \mathrm{~K}$ for $1.5 \mathrm{~h}$. Many white crystal grains are observed in the region of the dark field image, and the size of the crystal grains is relatively large, approximately $13 \mathrm{~nm}$. This is consistent with the above-calculated grain size, although the number of nano-grains is great, the amorphous matrix remains dominant. It can be observed from Fig. 6(b) that the number of nano-grains in the amorphous matrix increases, and the adjacent grains aggregate and grow to form larger grains. The higher annealing temperature increases the nucleation rate of nano-grains, and also provides better conditions for the grain growth. With an increase in the annealing temperature, the $\mathrm{Cu}_{10} \mathrm{Zr}_{7}+\mathrm{CuZr}_{2} \rightarrow \mathrm{CuZr}$ reaction occurs, leading to the formation of the plastic $\mathrm{CuZr}$ phases, this may result in better plasticity of the amorphous alloy at room temperature. In general, when the temperature is $706 \mathrm{~K}$, the microstructure evolves as follows: amorphous $\rightarrow \mathrm{Cu}_{10} \mathrm{Zr}_{7} \rightarrow \mathrm{Cu}_{10} \mathrm{Zr}_{7}+$ $\mathrm{CuZr}_{2}$. When the temperature is $726 \mathrm{~K}$, it evolves as follows: amorphous $\rightarrow \mathrm{CuZr}_{2}+\mathrm{AlCu}_{2} \mathrm{Zr}_{7}+\mathrm{Cu}_{10} \mathrm{Zr}_{7} \rightarrow \mathrm{Cu}_{10} \mathrm{Zr}_{7}+\mathrm{CuZr}_{2}$ $\rightarrow \mathrm{CuZr}_{2}+\mathrm{CuZr}(\mathrm{B} 2)+\mathrm{Cu}_{10} \mathrm{Zr}_{7}$. When the temperature is 746 $\mathrm{K}$, it evolves as follows: amorphous $\rightarrow \mathrm{Cu}_{10} \mathrm{Zr}_{7}+\mathrm{CuZr}_{2} \rightarrow$ $\mathrm{CuZr}_{2}+\mathrm{AlCu}_{2} \mathrm{Zr}_{7}+\mathrm{Cu}_{10} \mathrm{Zr}_{7}+\mathrm{CuZr}(\mathrm{B} 2) \rightarrow \mathrm{CuZr}_{2}+\mathrm{AlCu}_{2} \mathrm{Zr}_{7}$ $+\mathrm{CuZr}(\mathrm{B} 2)$ (increased) $+\mathrm{Cu}_{10} \mathrm{Zr}_{7}$.

\section{Conclusions}

(1) On the basis of the TMA and thermal expansion coefficient curves, the structural transformation behavior of the $\left(\mathrm{Cu}_{43} \mathrm{Zr}_{48} \mathrm{Al}_{9}\right)_{98} \mathrm{Y}_{2}$ amorphous alloy can be divided into five different stages: structural relaxation preparation stage, structural relaxation stage, first crystallization stage, second crystallization stage, and grain growth stage.

(2) The $\left(\mathrm{Cu}_{43} \mathrm{Zr}_{48} \mathrm{Al}_{9}\right)_{98} \mathrm{Y}_{2}$ amorphous alloys with different heating rates have different degrees of structural relaxation. When the heating rate is $20 \mathrm{~K} / \mathrm{min}$, the difference between the thermal expansion coefficient of as-cast $\left(\mathrm{Cu}_{43} \mathrm{Zr}_{48} \mathrm{Al}_{9}\right)_{98} \mathrm{Y}_{2}$ amorphous alloy and the minimum coefficient of thermal expansion is the smallest, the thermal stability of
$\left(\mathrm{Cu}_{43} \mathrm{Zr}_{48} \mathrm{Al}_{9}\right)_{98} \mathrm{Y}_{2}$ amorphous alloy is the best. The width of the supercooled liquid region is $66.42 \mathrm{~K}$.

(3) The structure evolution of the amorphous alloy with different relaxation states is as follows: amorphous $\rightarrow \mathrm{CuZr}_{2}$ $+\mathrm{AlCu}_{2} \mathrm{Zr}_{7} \rightarrow \mathrm{CuZr}_{2}+\mathrm{AlCu}_{2} \mathrm{Zr}_{7}+\mathrm{CuZr}(\mathrm{B} 2)+\mathrm{CuZr}(\mathrm{M})+$ $\mathrm{Cu}_{10} \mathrm{Zr}_{7} \rightarrow \mathrm{CuZr}_{2}+\mathrm{AlCu}_{2} \mathrm{Zr}_{7}+\mathrm{CuZr}(\mathrm{B} 2)+\mathrm{CuZr}(\mathrm{M})$.

(4) After annealing at $706 \mathrm{~K}$ and $726 \mathrm{~K}$, the nanocrystals sizes of the $\left(\mathrm{Cu}_{43} \mathrm{Zr}_{48} \mathrm{Al}_{9}\right)_{98} \mathrm{Y}_{2}$ amorphous alloys are $10 \mathrm{~nm}$ and $13 \mathrm{~nm}$, respectively. When the annealing temperature is $746 \mathrm{~K}$, the amorphous alloy is completely transformed into a crystalline alloy. When the annealing temperature is $706 \mathrm{~K}$, the crystallization process of the amorphous alloy is as follows: amorphous $\rightarrow \mathrm{Cu}_{10} \mathrm{Zr}_{7} \rightarrow \mathrm{Cu}_{10} \mathrm{Zr}_{7}+\mathrm{CuZr}_{2}$. When the annealing temperature is $726 \mathrm{~K}$, the crystallization process of the amorphous alloy is as follows: amorphous $\rightarrow \mathrm{CuZr}_{2}+$ $\mathrm{AlCu}_{2} \mathrm{Zr}_{7}+\mathrm{Cu}_{10} \mathrm{Zr}_{7} \rightarrow \mathrm{Cu}_{10} \mathrm{Zr}_{7}+\mathrm{CuZr}_{2} \rightarrow \mathrm{CuZr}_{2}+\mathrm{CuZr}(\mathrm{B} 2)$ $+\mathrm{Cu}_{10} \mathrm{Zr}_{7}$.

\section{Acknowledgements}

This work was financially supported by the Principal Fund of Xi'an Technological University, China (Grant No. 0852302021407).

\section{References}

[1] Wang You, Jiang Stephen, Wang Meidong, et al. Abrasive wear characteristics of plasma sprayed nanostructured alumina/ titania coatings. Wear, 2000, 237(2): 176-185.

[2] Botta W J, Berger J E, Kiminami C S, et al. Corrosion resistance of Fe-based amorphous alloys. Journal of Alloys and Compounds, 2014, 586(2): 105-110.

[3] Duan G, Wiest A, Lind M L, et al. Lightweight Ti-based bulk metallic glasses excluding late transition metals. Scripta Materialia, 2008, 58: 465-468.

[4] Park J M, Kim Y C, Kim W T, et al. Ti-Based Bulk Metallic Glasses with High Specific Strength. Materials Transactions, 2004, 45: 595-598

[5] Kim Y C, Kim W T, Kim D H. A development of Ti-based bulk metallic glass. Materials Science and Engineering: A, 2004, 375-377: 127-135. 
[6] Mei J N, Soubeyroux J L, Blandin J J, et al. Nanocrystallizationinduced large room-temperature compressive plastic strain of $\mathrm{Ti}_{40} \mathrm{Zr}_{25} \mathrm{Ni}_{8} \mathrm{Cu}_{9} \mathrm{Be}_{18} \mathrm{BMG}$. Journal of Alloys and Compounds, 2011, 509: 1626-1629.

[7] Zhang $Y$, Zhao D Q, Wang $R$ J, et al. Formation and properties of $\mathrm{Zr}_{48} \mathrm{Nb}_{8} \mathrm{Cu}_{14} \mathrm{Ni}_{12} \mathrm{Be}_{18}$ bulk metallic glass. Acta Materialia, 2003, 51: 1971-1979.

[8] Wang $\mathrm{W} \mathrm{H}$. The nature and characteristics of amorphous materials. Progress in Physics, 2013, 33(05): 177-351. (In Chinese)

[9] Wu L J, Zhu Z W, Liu D M, et al. Deformation behavior of a TiZr-based metallic glass composite containing dendrites in the supercooled liquid region. Journal of Materials Science and Technology, 2020, 37: 64-70.

[10] Shen Y, Perepezko J H. Al-based amorphous alloys: Glassforming ability, crystallization behavior and effects of minor alloying additions. Journal of Alloys and Compounds, 2016, 707: 3-11.

[11] Huang $X Q$, Xu H, Tan $X H$, et al. Crystallization and magnetic properties in $\mathrm{Fe}_{72-x} \mathrm{Nd}_{7} \mathrm{~B}_{21} \mathrm{Nb}_{x}(x=0-4.0)$ bulk alloys. Rare Metal Materials and Engineering, 2018, 47 (01): 214-218. (In Chinese)

[12] Komatsu T, Takeuchi M, Matusita K, et al. Study of structural relaxation of $\mathrm{Ni}_{78} \mathrm{Si}_{8} \mathrm{~B}_{14}$ metallic glass by electrical resistivity and thermal expansion measurements. Journal of NonCrystalline Solids, 1983, 57: 129-136.

[13] Pradeep K G, Herzer G P, et al. Atom probe tomography study of ultrahigh nanocrystallization rates in $\mathrm{FeSiNbBCu}$ soft magnetic amorphous alloys on rapid annealing. Acta Materialia, 2014, 68: 295-309.
[14] Mei J N, Soubeyroux J L, Blandin J J, et al. Structural relaxation of $\mathrm{Ti}_{40} \mathrm{Zr}_{25} \mathrm{Ni}_{8} \mathrm{Cu}_{9} \mathrm{Be}_{18}$ bulk metallic glass. Journal of Non-Crystalline Solids, 2011, 357(1): 110-115.

[15] Yang Y Z, Li X F, Qiu Z H, et al. Influences of Isothermal Heat Treatment on the Microstructure and Compression Properties of $\mathrm{Zr}_{57} \mathrm{Cu}_{15.4} \mathrm{Ni}_{12.6} \mathrm{Al}_{10} \mathrm{Nb}_{5}$ Bulk Amorphous Alloy. Rare Metal Materials and Engineering, 2006, 8: 1254-1257. (In Chinese)

[16] Yuan X P, Zhen S Z, Zhao Y C, et al. Crystallization behavior of $\mathrm{Cu}_{46} \mathrm{Zr}_{44} \mathrm{Al}_{5} \mathrm{Nb}_{5}$ bulk amorphous alloy. Rare Metals, 2013, 37(05): 738-743. (In Chinese)

[17] Cao Chengcheng, Fan Juewen, Zhu Li, et al. Effects of relaxation time on local structural and magnetic properties of $\mathrm{Fe}_{80.8} \mathrm{~B}_{10} \mathrm{P}_{8} \mathrm{Cu}_{1.2}$ amorphous. Acta Physica Sinica, 2017, 66(16): 259-266. (In Chinese)

[18] Chen Q J, Wang J, Shen J, et al. Thermal expansion characteristics and thermal conductivity of FeCo-based bulk amorphous alloys. Rare Metal Materials and Engineering, 2016, 45(03): 765-770. (In Chinese)

[19] Guan H, Kou H C, Wang J, et al. Study on structural transformation behavior of a Ti-Based bulk metallic glass by thermal expansion method. Rare Metal Materials and Engineering, 2014, 43(5): 1047-1050.

[20] Luborsky F E, Ke C, Tang Y S, et al. Amorphous Metallic Alloy. Beijing: Metallurgical Industry Press, 1989: 133.

[21] Porscha B, Neuhäuser H. Combined measurements of modulus and length and their correlation for different amorphous alloys. Scripta Metallurgica et Materialia, 1995, 32: 931-936.

[22] Wang Z Y, He J, Yang B J, et al. Liquid-liquid phase separation and formation of two glassy phases in $\mathrm{Zr}-\mathrm{Ce}-\mathrm{Co}-\mathrm{Cu}$ immiscible alloys. Acta Metallurgica Sinica, 2016, 52(11): 1379-1387. (In Chinese) 